\title{
PROBLEM BASED LEARNING AND THE CONSTRUCTION OF AN SLP CURRICULUM
}

Robert Fourie

Dept. Speech and Hearing Sciences, College of Medicine and Health, University College, Cork, Ireland

\section{Abstract}

Problem Based Learning(PBL) isa learner-centered, smallgrouplearning pedagogy that emphasizesknowledge as an emergent and socially constructed property of learners'relationships to information; and which is thought to bridge some of the issues related to the theory-practice gap in professional education. The current paper aims to explore the philosophical groundings of this method, some of the research pertaining to its use in SLP curricula; and practical suggestions for its application, based on the author's experiences of implementing this method in a new SLP curriculum at University College Cork (UCC), Republic of Ireland. Morespecifically, thispaperexaminesthetheoretical basisfor PBL, problemconstructionandsuggestionsfor how the method can be incorporated into an SLP curriculum at tertiary level.

\section{Key words: Problem Based Learning (PBL), Teaching and Learning, Curriculum development.}

Background and Philosophical Groundings of PBL There is too much information out there and our students are being overloaded with 1 more facts than they will ever be able to
remember in practice. This sentiment was expressed in the medical community as early as 1913 when Osler noted that medical curricula were growing at a phenomenal rate (Osler, 1913). Following Osler's comments, it became widely recognized that learners simply memorized facts for examinations, but then soon afterwards, iforgot this information (Wood, 2004). Moreover, traditional models of education in the West were at this time influenced by behaviourist accounts of learning such as those of Thorndike (1906) that focused on modelling, demonstration and reinforcement of closer attempts to match an ideal fixed fact or skill (Saettler, 1990). Such an approach assumed that reality was knowable, and that the learner's response could be objectively judged as right or wrong according to clear criteria.

This epistemology was reflective of the philosophy of Realism that dominated much of the $20^{\text {th }}$ century. Realism focused on the universal elements that constitute reality; but more importantly, stressed that these universals existed independent of the linguistic, cognitive and social practices of people (Miller,2005). Influenced by Platonic thought, Realism assumed that information was "particulate" in nature and that these "particles" of knowledge could be delivered to learners, bit by bit. Accordingly, the sign of someone who had learned sufficiently was their ability to return this information in an examination. This was proof that the learner's "inner reality" reflected the outer truth of reality. The implications of such an epistemology were that instruction should focus on clear transmission of information; and that learning constituted successful memorization of facts (Bonk \& Cunningham, 1998). Also heavily influenced by Descartes, who believed that any complex problem could be understood by reducing it to its elemental constituents, Realist epistemologies have generally promoted the study of ever smaller, or specialist segments for the purposes of constructing an understanding of the natural world.

To date, SLP departments have generally reflected this epistemology, by providing a modular, subject-based approach to delivering a curriculum. This distributed approach to curricular design is illustrated by taught subjects being situated across the university, with learners attending courses in linguistics, anatomy, physiology, audiology and education, in departments unaware of the curricular goals of SLP departments; and with limited explicit integration of these courses into a coherent whole. Consequently, it has been left up to SLP learners to somehow assimilate and synthesize these units of information into a meaningful gestalt for themselves; and then apply this to clinical situations.

Symbolic Interactionism on the other hand, as an

Author Contact: Dept. Speech and Hearing Sciences,

University College Cork, Brookfield Healtb Sciences Complex,

College Road, Cork, Ireland

Tel: +353214901538

E-mail: r.fourie@ucc.ie 
alternative epistemology, developed in opposition to Realism (Blumer, 1969); and formed the basis of many qualitative research methodologies. This humanistic philosophy presented humans as intersubjective; constructing their identities by using their imaginations to make meaningful interpretations of events, with each other, through language, and within a social context. Such a philosophy applied to learning, implied that knowledge was relational and dependent on how well the learner was able to interact with information and other people to generate knowledge. Symbolic Interactionism was reminiscent and influenced by John Dewey who argued for the active participation of learners in the process of learning (Dewey, 1929).

The implication of Symbolic Interactionism, as applied to learning, was that knowledge represented iterative relationships to socially mediated information; and that the goal of education, rather than to feed learners with "particles" of information, might be to foster a relationship in the learner to facts and information. Consequently, Symbolic Interactionism seeded the Constructivist approach to teaching and learning (Palincsar, 1998). From this perspective, learning was a process of entering into an active relationship with information which occurred in a network of social and cultural contexts (Palincsar, 1998). Constructivists therefore rejected the view that knowledge is situated in the learner; instead holding that knowledge could be better conceived of as arising from interaction with information in a social context.

Carl Rogers, in the early 1950's, enlarged on this concept by applying his client-centred theories to the arena of education and advocated for university learners to become more active in the acquisition of knowledge (Rogers, 1961). Rogers advocated a system in which learners collaborated on what they needed to know, worked together to attain that knowledge, and used it to accomplish something. From this Constructivist perspective, knowledge was more relational; knowledge was actively pursued and constructed; and was conceived of as a field of interaction, rather than an object that can be consumed and known. Like all relationships, knowledge could grow and change; it was dynamic and challenging to the individual, rather than being static, unchanging and merely additive in nature.

A relational understanding of knowledge allowed for change and dynamic growth of information, in the sense that learning was not simply the acquisition of a fact. From the Constructivist perspective, the learner was not a passive consumer of information (Palincsar, 1998). Instead, the learner had an attitude to a fact; was not uncritical in the understanding of a fact; and evaluated a fact from the perspective of previous information and relationships with other bodies of knowledge, within a social context (Savery \& Duffy, 2001). For this reason, learners were seen to need opportunities to apply information within a community of practice. Knowledge was negotiated and tested in context; and knowledge and learning were seen as social (Palincsar, 1998). Moreover, explaining one's thought and understanding of a topic in an interactive situation enabled a deeper processing of information (Bereiter \& Scardamalia, 1989). And thus, the social dimensions of communication therefore facilitate the growth of deep knowledge (Palincsar,
1998).

\section{Problem Based Learning (PBL)}

PBL endorses a constructivist epistemology inasmuch as the learner constructs knowledge in a social context, rather than having it passed on to them (Haith-Cooper, 2000). The development of PBL occurred in reaction to discontent with how medical learners were taught in Canada (Barrows, 1996). Barrows explains that teachers at McMaster University Medical School in Hamilton Ontario in the 1960 s decided to experiment with new methods of teaching that incorporated ideas from various previous theorists. Accordingly, PBL developed with a number of core characteristics as follows:

(i) Learner centeredness

(ii) Small group learning

(iii) Facilitation by tutors

(iv) Interacting with iconic problems

(v) Problems facilitate knowledge and skills

(vi) Self-directed learning (Barrows, 1996).

In addition, $\mathrm{PBL}$ as a method, recognized the relational and discursive nature of learning. Firstly, from the perspective of the relationship between the learner and information and secondly, from the perspective of the social relationships in which such knowledge was constructed. Moreover, PBL allowed learners to actively:

(i) Create meanings from evidence, facts and information,

(ii) Negotiate the meanings these facts had in relation to a specific learning outcome,

(iii) Co-construct meanings in a social milieu (Hmelo-Silver \& Barrows, 2006).

This meant that learners provided the power for the process of learning; learning was owned by learners; and learning occurred in a realistic social context that better emulated a real-life work environment than the classroom lecture, in which the learner was a passive and uncritical recipient of the lecturer's dictated notes. It therefore located the learner in a particular active relationship to information which was dynamic and ever-changing. In this student driven learning, learners drive the discussion, while the PBL facilitator scaffolds the process of learning (Collins, Brown \& Newman, 1989).

More specifically, PBL is a methodology for teaching and learning that involves active, small group learning that focuse on investigating and explaining a meaningful problem (Barrows, 2000). Learners meet in small groups of seven to nine individuals and are facilitated by a PBL facilitator. Essentially, a problem is a narrative or artefact that triggers enquiry and the growth of knowledge. On analyzing the problem, learners identify the relevant information provided in the problem; and this allows the learners to meaningfully represent the problem, so that a process of hypothesizing can ensue (Hmelo-Silver, 2004). This means that learners try to predict what the issues and consequences of the problem might be, prior to formal study. This process of hypothesizing leads naturally to defining knowledge deficiencies which 
become the learners' "learning issues", and which fuel the process of self-directed learning (Hmelo-Silver, 2004). Once learning issues have been set, learners leave the tutorial and access literature over the next few days. This literature may provide solutions to the learning issues and may help the learners confirm or disconfirm their hypotheses (HmeloSilver, 2004). On reconvening a few days later in a tutorial, learners are provided with opportunities for in-depth discussions of their findings. These discussions foster the application of their new-found knowledge to the problem trigger, their hypotheses and their learning issues (Barrows, 2000). During this process, notes are taken on a blackboard and learners make attempts to answer their learning issues. Finally, at the completion of a problem, learners hand in academic journals which are essentially short essays that reflect the synthesis of knowledge that occur in tutorials and which demonstrate the learners' practical application of their learning to the characters and elements in the problem. These partly replace lecture notes on the topic in question. PBL therefore achieves a number of goals in relation to learning:

(i) The development of a professional knowledge base

(ii) Problem solving skills

(iii) Life long self-directed learning

(iv) Social collaboration

(v) Motivation to learn (Barrows \& Kelson, 1995).

In an SLP curriculum,a set of problems elicits a part, but preferably the entire curriculum. This means that the faculty involved in the delivery of such a curriculum, need to decide in consultation with statutory professional bodies and other departments, how widely the PBL curriculum can be incorporated into the overall SLP curriculum. Ideally, all aspects of an SLP curriculum could be delivered using an integrated PBL approach. This means that psychology, linguistics, communication disorders, audiology, education, neurology and physiology might all be delivered as a series of coherent problem triggers that are integrated to form a complete curriculum. This may not be entirely achievable; but in the author's experience it is sufficient to incorporate some of the disciplines; and parts of the essential aspects of others. However, when a discipline other than SLP, such as psychology is involved in such an approach, then its modules should reflect this inclusion within the SLP curriculum; and therefore, an associated reduction in formal psychology lecturing contact. In other words, PBL should not double student workload or contact.

In line with a constructivist epistemology of learning, each problem would incorporate a number of subject areas simultaneously, rather than simply embodying a different subject area in each problem. According to Barrows (1998), PBL should aim to facilitate the acquisition of knowledge on a deep level thus developing clinical problem solving; and that this could be attained by integrating various disciplines into each problem. Curriculum developers should work collaboratively with other disciplines to incorporate the relevant aspects into the SLP curriculum.
Thus, PBL is essentially an interdisciplinary venture involving the social collaboration of lecturing staff, adjunct lecturers (PBL facilitators), learners and different faculties. Such collaboration can have positive spin offs such as interdisciplinary research and community development.

\section{Research In PBL for SLP curricula}

There are only a few studies evaluating the utility of PBL in the field of SLP; but these are mostly related to the student experience. For example, Murphy (2004) studied 1st and 2nd year SLP learners' experiences of PBL in the context of a psychology curriculum using a questionnaire. Murphy reported that learners experiencing this curriculum, valued both the team work and involvement in in-depth learning; but perceived the method as increasing their expected workload. This finding by Murphy might be explained by learners being used to passive learning as experienced in other more traditional courses or an unreported addition of PBL to a standard psychology lecturing curriculum. In addition, Murphy's participants felt that interpersonal communication was somewhat awkward between some learners new to this method (Murphy, 2004). Leahy, Dodd, Walshe \& Murphy (2006) conducted a similar attitudes study with 2nd, 3rd and 4th year students in addition to MSc learners in SLP curricula in two centres; one in Ireland and another in the UK. These researchers reported descriptive statistics indicating $71 \%$ of their two participant samples believed that PBL was relevant to practice, but only $58 \%$ believed that PBL was sufficient for preparation to practice. It is not clear from these studies how various disciplines were integrated into the PBL curriculum; or if this method was incorporated only into a single module. Fourie and Fletcher (2006) conducted a questionnaire study to evaluate learners' attitudes to PBL following a foundation year in a newly formed SLP curriculum, in which communication disorders, psychology and linguistics were mostly delivered in an integrated PBL format; with a few supplementary workshop-type lectures for practical skills such as phonetic transcription and language analysis. Twenty three respondents completed an anonymous questionnaire indicating agreement or disagreement on visual analogue scales (VAS) eliciting attitudinal constructs in relation to their experience of PBL. Participants in this study generally agreed that they enjoyed group sharing and discussion and agreed that PBL engendered critical and clearer thinking, self-directed learning and the improvement of communication skills in a group context. However, participants were equivocal with regards to their attitudes to the differential contributions of members in a group, mutual support and resource sharing. In summary, most of the SLP studies assessing learner experiences, generally seem to agree that learners perceive benefits and some shortcomings of the PBL method. Furthermore, as Colliver (2002) notes, widely reported student satisfaction and preference for PBL in the field of medicine, does not guarantee practitioner competence.

There are no extant studies in the field of SLP education clearly differentiating the academic and clinical outcomes of traditional learning versus PBL. Relevant research outside of the discipline, mainly focuses on knowledge competency following exposure to PBL (Koh, Khoo, Wong and Koh, 


\section{ROBERT FOURIE}

2008); and there have been controversies in relation to whether PBL results in a weaker knowledge base in medical students (Colliver, 2002; Vernon \& Blake, 1993). Koh and colleagues (2008), in a recent systematic review assessing 15 controlled studies meeting their inclusion criteria, determined that while learners graduating from PBL curricula perceive themselves as having less knowledge than their non-PBL schooled peers, that there was no evidence to support this. Moreover, their study provided evidence that PBL had positive effects on both the social and cognitive dimensions of physician practice. Readers are referred to Koh and colleagues' interesting analysis of pre-existing literature on PBL outcomes in the medical education literature (Koh, et al., 2008).

Constructing a PBL curriculum

The following description is based on the author's experience and understanding of developing a PBL curriculum for a Cork-based SLP programme in Ireland, which was based on an earlier University of Hong Kong curriculum, modified and "Hibernosized" for the Irish context. These ideas for constructing a PBL curriculum are not intended to be prescriptive; but instead to provide suggestions for how PBL might be incorporated, in whole or in part, into an SLP curriculum.

\section{The Curriculum Matrix}

A departmental curriculum committee, prior to developing a set of problems for an SLP curriculum, needs to develop a curriculum matrix that will help organize and systematize the curricular content of a course (Barrows, 1994). A curriculum matrix is a set of carefully defined learning areas for each year of the entire SLP curriculum. Learning areas for the entire curriculum need to be decided upon prior to devising problems; and these learning areas need to be associated into similar 'knowledge groups'. For example, phonology and motor speech disorders in childhood could be grouped into a family of learning areas relating to expressive problems in the paediatric population. In this way, a taxonomy of learning areas should be devised by a curriculum committee.

Learning areas in SLP are the major subdivisions of the core topics of SLP. In some SLP curricula, the first year consists of a general introduction to communication disorders, while the second and third years incorporate paediatric and adult areas of an SLP curriculum respectively. Devising a curriculum matrix should be based on the general topics pertinent to SLP that accrediting bodies have determined to be the main areas of learning for the profession. Essentially, a curriculum committee, based on local norms, can decide exactly what areas of knowledge need to be accessed by learners, so that they can become SLPs. Often, such information may already exist in documents pertaining to the curricular goals of an SLP programme; or they can be distilled from lists of learning outcomes based on Bloom's (1956) taxonomy, appropriate to a particular programme. The following is a sample of a core topic and its associated learning areas in year one.

1) Phonology (Year 1):

Normal development of speech during pre-school years
Relationship between speech and social
development in early years
Phonological processes
Risk factors for delayed and disordered speech

In addition, a number of learning outcomes, based on Bloom's original (1956) taxonomy, can be stipulated for these learning areas. For example, the following learning outcomes are associated with the above topic and learning areas:

Learners should be able to:

Describe the typical development of speech sounds,

Explain, with examples what is a phonological process,

Distinguish between typical and atypical phonological processes,

Appreciate the psychosocial effects of speech impairment in an affected child.

The above learning areas and learning outcomes are appropriate for an introductory level course. However, at a second year level, further learning areas might be added to a topic in a way that reflects the developmental level of the learner:

Phonology (Year 2):
Intelligibility
Analysis of child phonology
Relationships between child and adult
phonology
Contribution of vowel errors to intelligibility
$\begin{aligned} & \text { Assessment and treatment of consonant and } \\ & \text { vowel processes }\end{aligned}$

The associated learning outcomes for these learning areas in the second year might include:

Perform a consonantal relational analysis of a paediatric speech sample.

Interpret phonological analyses for the purpose of designing intervention.

Calculate Percentage Consonants Correct (PCC) in a speech sample

Calculate Percentage Words Correct (PWC) in a speech sample

Classify vowels into their various phonetic and phonological categories

Calculate Percentage Vowels Correct (PVC) in a speech sample

Compare summary measures to normative data.

Each program may differ according to the specific emphasis it has. Also, learning areas should not include only communication disorders. Learning areas should incorporate cognate areas pertinent to communication disorders. The following are examples of such learning areas: 
the scientific method

linguistic theories of child language development

psycholinguistic models of speech and language

processing

developmental theories in psychology

phonetics and IPA transcription

grammatical analysis

learning, memory and cognition

the neurology of speech, language and hearing

Once a comprehensive set of learning areas and associated learning outcomes have been determined for each year of a curriculum, the learning areas can be distributed throughout a number of problems that will form the focus for learning during the academic semester. The curriculum committee needs to decide what learning areas should be contained in each problem; and these learning areas need to be clustered in plausible ways. However, it is important that there is some unexpected pairing of learning areas in order to create surprise and to reflect the unpredictability of clinical practice in SLP. So for example, a problem on "Neurogenic voice disorders" may be paired with "the construction and enactment of intervention". A problem on closed head injury might contain learning issues pertaining to the "social and psychological consequences of closed head injury" together with the learning issue of "evidence based practice". Thus problems have content which is related in a non-linear and often surprising way, which may reflect the realities of practice. Examples of plausible pairings include

Attention deficit disorders and medical
anthropology
Stammering and personality theory
Specific language impairment and measurement
of intelligence
Personal adjustment counselling \& neurogenic
voice
Laryngeal cancer and lifespan psychology of late
middle-age
Cleft palate and the psychology of disfigurement

On a more practical level, once learning areas have been outlined, a curriculum committee needs to know how many problems they need for each year of study and how those problems will be divided into the semester structure of the college. Some SLP programs incorporating PBL, include more learning areas in fewer problems, while other programs have more problems with fewer learning areas in each. If the curriculum committee decides for example, to have fifteen problems per year, they need to decide what the focus of each year will be. So for example, first year may be a general introduction to paediatric and adult communication and development; with second year focusing on paediatric disorders of communication; and third year focussing on adult disorders of communication. This depends on how the faculty understands the developmental sequence of learning for their learners.

Typically, each, member of a curriculum committee becomes a "case manager" and is assigned a number of problems to devise, manage and regularly update, according to their general areas of expertise. Part-time staff or independent consultants can also be involved in this process with responsibility for possibly fewer cases in more specialized topics. In addition, case managers can work together to incorporate different aspects of a complex topic into a single problem. It is important however, that case managers have some experience in the areas covered in the problem, so that the problem trigger can be written from experience and therefore have ecological validity; or can be taken from a real case, and made anonymous for the purposes of confidentiality. Also, if the case manager has experience in the learning areas covered in the problem, it is more likely that he or she will have access to data and artefacts relevant to the problems. So for example, a problem containing reference to acquired profound hearing loss in adulthood may need to include audiograms and other electrophysiological data. Once case managers have been assigned, it is their responsibility to construct a problem or problems that relates to the learning areas they have been allocated. However, problems need to be carefully constructed and it is therefore necessary to examine what a problem is in a little closer detail.

\section{What is a Problem?}

Before entering into definitions of the problem in the context of PBL, it is relevant to examine the notion of "problem" generically. Essentially, a problem is an anomaly that calls for explanation or response; and is therefore a challenge to responsibility. Accordingly, a problem presents an opportunity to apply old knowledge and in the process, synthesize new knowledge. Thus a problem carries within it the potential for transformation. However, a problem implies an expenditure of energy: effort is required to create a transformation. If something did not involve effort, or was properly understood then it would not be a problem. Therefore, a problem can also be seen as a kind of gateway to knowledge and personal transformation that involves personal effort.

A significant portion of what is discussed in a PBL tutorial involves conversation around a textual trigger or problem; although videos, live clients and other artefactual objects can also be used. A problem is usually a state or an event, and its structure can be easily reflected within a narrative framework. In the context of PBL, a problem is for all intents and purposes, an interesting, meaningful and educationally relevant narrative and it consists of events that need to be explained (Norman \& Schmidt, 1992). Problems should be "ill-defined", complex and reflective of the real world. Carder, Willingham and Bibb (2001) explain that "illdefined" means that a problem does not have a specific single solution; thus reflecting the reality of practice. However, it is a trigger that is amenable to discussion and the making of meaning. Such discussions mostly involve the analysis of text and it is therefore important to understand what makes various aspects of such narrative texts meaningful or salient to learners.

In the context of communication disorders, a problem is a plausible and ecologically valid story about either a client with a communication or swallowing disorder; and/or about an SLP, with the purpose of bringing to the learner's attention, experiences that might be salient to the practice 


\section{ROBERT FOURIE}

of SLP. Therefore, a problem has an explicit purpose: It enables learners to construct the various facets of what it means to be an SLP, in a particular context. It is therefore designed to evoke the meanings, professional values and knowledge that SLPs need to set in motion to perform their profession. The problem is therefore an exemplar of an SLP issue relevant to becoming an SLP, told as a story or part of a story. In PBL, such contexts for learning are stories that are constructed as a "problem".

\section{The Problem As Narrative}

The work of the SLP is transformative and therefore involves stories of change. Thus, the problem trigger may be identified as a meaning-generating narrative - and as a narrative, it will follow the laws of narrative discourse. Thus, every problem is framed as a story and is constructed according to a story grammar: It has a beginning, a middle and an end, like any good story does.

It is necessary to understand what makes these stories meaningful to learners. Stories are complex and non-linear, reflecting the complex nature of society. It is this complexity that makes humans love stories. This is evidenced by the value we place on television, cinema, radio, the reading of novels. Thus it makes sense to present information and a context for learning in the framework of a story. Symbolic Interactionism (Blumer, 1969) predicts that we are relational beings, looking for patterns of information in order to construct our own stories and to make meanings of the things we experience.

\section{Story Grammars for Problem Construction}

The construction of a story is not that straightforward, particularly when that story is textual. Thorndyke (1977) argued for a propositional-structural model of stories: that stories have their own grammar and consistent internal structures. Thorndyke outlined the structure of a story as consisting of a setting, which is the character list located in time and space; a theme, which is an event with a goal; a plot, which is a problem or a series of problems containing attempts to solve problems; and finally a resolution which is a specific event/state. These components were stated as rules in the format:

\section{Story $\Rightarrow$ Setting + Theme + Plot + Resolution}

Thorndyke described his narrative schema as a "frame" with its abstract components instantiated by specific details. Stein and Glenn (1979) has a slightly different way of formalizing the story grammar. Their story was structured according to the following format:

Story $=>$ Setting + Initiating Event +

Internal Response + Attempt + Consequence

In this grammar, which is framed slightly differently to Thorndyke's frame, the plot is subsumed by greater specification from the perspective of the actors in the story and the theme of the story is absorbed into the setting. There are a number of other story grammars, but these two represent the most commonly referenced story grammars and would be familiar to SLPs working on discourse in language therapy.
It is not sufficient to specify the abstract components of a story. It is also important that these components are held together in a coherent manner (Carroll, 1994). Therefore, sentences need to "tie" together sufficiently and make appropriate anaphoric reference to indexed members of the narrative. Indeed, the degree to which the reader will appropriately assimilate information in a text, will depend in part on how the reader processes that informational content (Chambliss, 1995). The adequate processing of information will depend on a number of factors, some of which are intrinsic to the learner and others of which will be dependent on the text presented to the learner.

\section{Textual Narrative Considerations}

Before engaging with text, there are a number of attributes of learners that will determine how they interact with textual problems. Firstly, it is necessary that learners have a need for cognition which can be defined as a "tendency to engage in and enjoy thinking" (Cacioppo \& Petty, 1982, p. 116). Secondly, topic interest refers to how likely a learner will have positive affect in relation to particular content (Renninger, 2000); and thus the significance of such material is probably mediated by the learner's value system and affective experience (Hidi \& Baird, 1988). Moreover, learners who have personal interest in the topic, are more likely to process information in text (Hidi, 1990). These intrinsic factors intervene in the likelihood of learners to engage with text. On the other hand, factors extrinsic to the learner and located within the structure of text also have a mediating role in how textual problems are processed.

"Interestingness" refers to how well learners will respond to a text (Hidi \& Baird, 1988). For example, textual information which is highly interesting is more easily recalled than text of less interest (Shirey \& Reynolds, 1988). Schank (1979) was one of the first researchers to discuss interestingness in the context of discourse processing. According to Schank, material is more interesting when it is non-normative, such as when things don't go according to expectation; when there is missing information which causes puzzlement and when the themes elicit "absolute interest", i.e. they are of an archetypal nature, such as death', sex and power (Schank, 1979). However, it is important to recognise that while text can be made artificially interesting; this may not necessarily facilitate important generalizations; instead it may detract from such important processes (Garner, Alexander, Gillingham, Kulikowich \& Brown, 1991). Therefore, when constructing problems, the author needs to make problems interesting; but not in a manner that may detract from their meaningfulness, in relation to communication disorders.

Dole and Sinatra (1998) state that motivation in learners to engage with text is determined by their dissatisfaction with their current state of knowledge, the personal relevance the information has for them, its social context and their own need for cognition. These researchers hypothesize that there is an interaction between learner characteristics and with characteristics of the text that result in meaningful engagement with the text. They suggest that text should be coherent, plausible, interesting and rhetorically compelling.

Dissatisfaction with the current state of knowledge is referred to as cognitive dissonance (Festinger, 1957; 
Neighbour, 1992). In the context of learning, cognitive dissonance is a psychological state in which the learner feels dissatisfaction at not knowing. Savery and Duffy (2001) call this cognitive "conflict" and state that this conflict determines what the learner will focus on and what prior knowledge the learner will invoke as relevant to constructing new knowledge. The problem should therefore induce in learners a need to want to find out. An individual experiencing cognitive dissonance, feels motivated to reduce it and to engage in behaviours reducing this dissonance. Therefore, an incongruity between the learner's previous understanding and current experience are what drives learning (Palincsar, 1998). Therefore, cognitive dissonance prompts the learner to find out; and it is essential for the accommodation of new ideas and information. Cognitive dissonance is similar to a need for cognition, in that it motivates behaviour, but is more goal-directed. While a need for cognition is an intrinsic individual trait that probably cannot be modified externally, cognitive dissonance is a state which can be induced in the learner by providing the learner with information that challenges understanding or creates a sense of puzzlement or questioning. According to Perret-Clermont, (1980) it is this "cognitive conflict created by social interaction" (p.12) where intellectual strides are made. This cognitive dissonance results in pertinent questions; and it is this questioning that is made explicit in the inventory of learning issues which learners formulate prior to accessing literature and making enquiry. Without this invoked sense of needing to know, the self-directed learning process is rudderless.

\section{Relevance and Ecological Validity}

The case manager should devise a problem that is ecologically valid. This refers to whether a problem is plausible, structured and coherent (Gonzalez \& Salmoni, 2008). This means that the problem should be interesting, but not full of distracting facts; it should be relevant to the curriculum; and it should contain supporting data and artefacts to corroborate and accentuate the ideas it aims to draw out in the learner. The problem is written in such a way that it will create a series of cognitive dissonances in learners that will inevitably lead them to ask relevant questions to answer their uncertainties. In order to write a plausible problem, the case manager needs not only to have some experience in that particular field, but also to be guided by evidence and literature in the fields covered by the learning areas.

The Professional Socialization of Learners through Narrative

If problems are not very carefully constructed to show faithfulness to complex issues in the life of clients and patients, they can inadvertently transmit unwanted assumptions, values and beliefs to learners (Kenny \& Beagan, 2004), that are neither advantageous to the profession of SLP, nor effective for the multifaceted treatment of clients and patients. While learners need to be exposed to problems that will closely resemble their future occupational situation (Dolmans, 1997), problems and case histories can depersonalize the client, reducing and separating the client into a list of symptoms (Anspach, 1988). Such a list may be useful to the practitioner as the end of a process of interview and assessment, but is not representative of what learners will encounter when dealing with clients (Kenny \& Beagan, 2004).

In fact, narratives presenting clients as a distilled list of symptoms may effectively distort the client's life by situating them out of time and context. In addition, the use of certain linguistic features may create further problems. For example, the use of the passive voice, imbues authoritative and factual status to the omitted practitioner (Anspach, 1988); for example: "The client was assessed", and "the PALPA was administered". Other linguistic markers might encode scepticism regarding client narratives, for example: "the client claims", or "the client reports". Passive sentences used together with such sceptical descriptors transmit an attitude that the practitioner is in control and that the client's story is not to be trusted. Kenny \& Beagan illustrate the power of language in a problem statement from a medical curriculum:

For example, in one case, after a patient "was referred to a respirologist", he "underwent bronchoscopy". Shortly afterwards a "chest $\mathrm{X}$-ray showed a $50 \%$ pneumothorax" so "a chest tube was inserted". He "was admitted to hospital" where "the chest tube continued to bubble".

Here no one performed the bronchoscopy (let alone cleaned the bronchoscope, wheeled the patient into the room, or cleaned up afterward); no one took the $\mathrm{X}$-ray, or read it; no one inserted the chest tube; no one admitted the patient, nor did the patient enter the hospital himself. The most active agents here were the $\mathrm{X}$-ray showing, and the chest tube bubbling! (Kenny \& Beagan, 2004, pp. 1073 - 1074).

Kenny and Beagan (2004) further point out that the presence of the client as an actual real person who experiences impact is often omitted in problems and they further imply that such characterizations may ultimately erode the learners' ethical sensitivities. They recommend the use of live clients where possible, the use of dense texts (containing richly detailed information about the client), the use of video, web technologies, photographs, transcripts and diary entries, among other things, to more richly portray the complexities of real live clients.

\section{Professional and Inter-disciplinary Issues}

In addition to issues regarding the self-directed learning process of learners and how the problem should be structured, there are other issues to consider in the development of problem triggers for an SLP curriculum. The fact that SLP is practice-oriented and governed by statutory bodies and legal parameters in most countries, means that the set of problems in an entire curriculum should be reflective of the typical principles and practices an SLP would need in the field as outlined by the statutory bodies. However, no curriculum can ever cover every aspect of knowledge pertinent to the field of SLP. This is because the fields of communication disorders, psychology, linguistics and physiology pertinent to speech disorders is so vast and ever-expanding. This is partly due to the explosion of available information in an information age dominated by the internet. Indeed, the drive to attempt to cover every possible piece of information 
relevant to a topic is part of a Realist epistemology. But, it is not possible to cover everything. Nevertheless, it is possible to expose learners to core exemplars of essential knowledge pertinent to the practice of SLP that might facilitate an intelligent and critical evaluation of available information. There is therefore, to some extent, a tension between compulsory components of a curriculum and the facilitation of an intelligent and critical attitude to knowledge that is the essence of the SLP; and which facilitates life long learning.

Unfortunately, a curriculum committee can become divided along Realist/Constructivist epistemologies and it is therefore important that PBL does not become divisive in the delivery of SLP curricula. To this end, it is important to find a middle ground between process and content. The role of the PBL curriculum designers is therefore to devise problems that will simultaneously serve as core exemplars of factual knowledge, while evoking the principled attitudes, cognitions and activities of the SLP working in a field which is not always typical or linear; and indeed changing rapidly.

Evaluating Current Suitable Literature

In a pure PBL approach, learners are left to find appropriate literature pertinent to their learning issues, themselves. While this is basic to the spirit of enquiry based learning, it may not always be appropriate for professional courses, particularly if there is not excellent library support. Although PBL is loosely based on principles of adult learning, many professional undergraduate programs deliver curricula to 17 and 18 year old learners. Such individuals may have achieved legal adulthood in most countries, but most individuals at this age are still teenagers. Although they may be cognitively mature, they may not have the adult experience or affective maturity to properly evaluate the level of reading that would be expected of them. In addition, learners from certain secondary schools may have been over-coached into graduation; resulting in learners who despite high achievement on final leaving certificate examinations, find it difficult to responsibly source, evaluate and apply academic information. For this reason, the current author recommends that first and second year learners be recommended prescribed texts to evaluate and read, while simultaneously be encouraged to bring their own researched material to tutorials. Later in third or fourth year, learners should know the level of reading required, and will also have matured into adulthood proper. They can then be at least partly expected to find the appropriate literature for achieving their academic goals.

Therefore, each case manager needs to prescribe appropriate texts, and this involves evaluating current literature relevant to the learning areas. Case mangers can recommend academic papers and expository texts that either cover the individual learning areas or the specific combination of learning areas, or both. This entails a robust attempt to assess the current available literature and to make decisions on what literature would be suitable to the learners' developmental level. To this end, the case manager has to find relevant scientific literature that illuminates the learning areas contained in the problem. This can be time-consuming, but is absolutely essential to not only present a plausible problem for learners, but one that will highlight current issues in the field pertaining to the problem. The implication of this is that problems can become stale or dated, as new evidence is produced in the scientific literature. Accordingly, one of the duties of the case manager is to continually evaluate the relevance and up-to-datedness of the problems he or she manages and this can be achieved by annual intra-faculty curricular committee meetings. Such meetings, while labour intensive also serve to enable departments to continually revise and improve their curriculum annually. In this way, problems remain fresh and will elicit issues that are current and relevant to the learner.

Introductory text-book chapters and secondary sources are often more digestible to first year learners who may need simpler and easier expository texts. Similarly, case managers need to consider that learners may be second language users of English, in which most SLP texts are published. The issue of cognitive academic language proficiency (CALP) is particularly important in this regard (Cummins, 1984, 1986); and case managers need to carefully select texts that are not too difficult for second language users; as this may be disempowering within any learning process. However, the PBL process allows students to express their difficulties with texts and allows those within the group, with a better grasp of a particular text, to share their insights and understanding with other members of the PBL group. As learners progress, texts which are a little more advanced can be prescribed.

Also, there is no harm in presenting learners with texts which are a little beyond their current developmental level. Vygotsy (1978) discusses the principle of working within the learner's zone of proximal development (ZPD). ZPD is a level of difficulty just a little advanced from the learner's current state of understanding. If material is presented that is too easy, learners will lose interest (particularly if they have a strong need for cognition) and conversely, if the material is too advanced for the learner, they will not feel capable of understanding and will give up on the text. It is therefore important that the case manager carefully select texts which will challenge learners but neither bore them nor over-challenge them.

A list of recommended (or compulsory) readings for each problem can then be provided to learners for evaluating and informing the learning issues raised in PBL tutorials. The devising of a coherent set of problems is the first step in devising a PBL curriculum.

\section{Problem Sample}

The following is an example of a problem written by the current author, according to this schema. It is situated in a third year curriculum focussing on adult communication disorders and has been "South Africanised" to suit local contexts:

\section{Voice Spasms, or "After ukufa komyeni wami." \\ Case Manager: Dr. R. Fourie}

Thandi was a 27-year-old postal clerk who worked in Randburg. Thandi had a personal tragedy in which her beloved busband had been killed in an MVA; and which some professionals believed bad resulted in a voice problem. An ENT referred Thandi to an SLP. 


\section{PROBLEM BASED LEARNING AND THE CONSTRUCTION OF AN SLP CURRICULUM}

It also had become obvious to Thandi and her family that her voice had deteriorated quite severely after ber loss because they kept having to ask ber to repeat herself due to ber weak and strained voice. A psychologist's report stated that besides the death of her busband, there were no other obvious psychopatbological factors at play in Thandis case. Since there were no obvious causal factors besides Thandi's husband's death, and the report from the ENT stating that there was no evidence of any kind of physiological pathology, Dr. Mary Nthebe, an SLP practicing near Thandi in Randburg, diagnosed a functional voice disorder. Thandi then commenced for voice therapy with $\mathrm{Dr}$ Nthebe, four months after her busband's death. But Dr. Nthebe realized after three sessions that Thandi's voice problem seemed intractable.

At first the voice was weak and intermittent, and Thandi complained that she felt there was "something stuck in ber tbroat like a "small ifishbone kanje. After ukufa komyeni wami". Throat clearing did not release her voice and gradually the voice became more strained and started showing an intermittent strangled barsh quality. Dr Nthebe referred back to the ENT who again, could find no obvious organic causes. It was at this time that the ENT diagnosed, with the assistance of a specialist $S L P$ trained in electroglottography (EGG), the presence of Adductor Spasmodic Dysphonia (see data).

Thandi went back to Dr. Nthebe, feeling very demoralised after the new diagnosis because firstly, she believed her family "thought it was all in ber head" and this was upsetting for her: "Do they think I am a bypochondriac? Awu ngiphe amandla, "Nkosi yami". She felt nobody understood what it was like for her. Secondly, she wanted to know why the doctors wanted ber to try Botulism as a medicine. "Surely that will kill me", said Thandi, "but maybe that will be good. I can join my beloved busband ezulwini. Akekbo onjengaye". Dr Nthebe understood that Thandi meant Botulinum toxin (BOTOX) treatment for spasmodic dysphonia, and felt worried about Thandi's mental health. Dr. Nthebe looked down at her report from the specialist SLP and wondered bow his report could possibly bave any real meaning in relation to Thandis suffering. This is what she looked at:

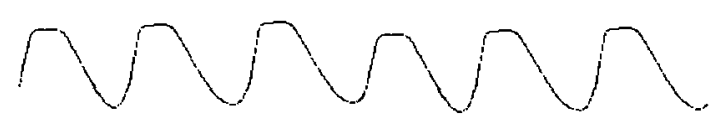

\section{$E G G$}

\section{Dear Dr. Nthebe}

The peaks of the waves in this EGG represent the closure part of the vibratory cycle of the vocal folds; while the "valleys" represent the open part of the vibratory cycle. By using standard measurements of the EGG graph above, and using the formula $C Q=$ $t C /(t C+t O)$ I bave determined that Thandi's vocal folds bave a 0.7 closed quotient, indicating possible adductor spasmodic dysphonia.

Kind regards

Jannie Vermeulen, SLP

Dr. Nthebe decided to make some Rooibos tea to share with her client, to belp calm Thandi's mind, before explaining the issues to her distressed client.

Product: Role play Dr. Nthebe's conversation with Thandi.

\section{Learning Issues}

In the above problem, the following may represent questions or learning issues learners might come up with as pertinent to the problem:

What is spasmodic dysphonia?

What is a functional voice disorder?

Why did the SLP first think the problem was functional?

How can an SLP differentiate between two types of voice disorder?

How does a functional voice disorder differ from spasmodic dysphonia?

What is electroglottography and how does it work?

What is the significance of the closed quotient and the EGG graph?

What is the role of the ENT in the diagnosis of voice disorders and how do these two professions work together?

What, if any, are the neurological bases of spasmodic dysphonia?

Why is BOTOX used with Spasmodic Dysphonia?

How can the SLP answer the client's concerns about the problem being "all in her head"?

What is the role of the psychologist in voice disorders?

What is the role of the SLP in relation to counselling the client?

Once hypotheses have been made about the problem and learning areas have been formulated, learners can access the literature in a meaningful way. Reading alleviates the cognitive dissonances learners experience as they resolve the questions raised in the learning issues. Once learners have accessed online resources and relevant expository texts available in the campus libraries (or provided by the department), the learners are ready to discuss what they have learned with each other. Learners evaluate the literature and find resources to be brought to the tutorial for discussion. It is at this point that the PBL facilitator could help the learners evaluate the quality of the information in relation to the requirements of the profession.

Evaluating the Problem Prior to Learner Exposure

Once case managers have completed designing a problem, they might want to ask the following questions of the problem, to determine whether it is suitable for the program: 
Does this problem represent a recognized core area or field in the profession of SLP?

Does the problem have ecological validity, i.e. does it seem plausible from the perspective of a practitioner? Have I seen a similar case myself?

Does the problem have good narrative structure and connectivity?

Does the problem take account of the complexity and non-linearity of practice?

Does this problem promote conceptual thinking and development?

Does this problem engage the reader affectively in some manner?

Does this problem allow the possibility of relating theory to appropriate practice?

Does this problem have any data or artefactual information for the learner to grapple with and process?

Does this problem elicit current thinking on the topic?

Is their sufficient recommended literature that takes into account the learners' developmental level?

Is the problem narrative culturally appropriate? Does the narrative reflect a changing multi-cultural society?

Are there too many red herrings or distracting pieces of information in the problem?

The Structure of the PBL session

According to Barrows (1994), PBL tutorials should progress in the following order:

Ideas \& Hypotheses $=>$ Facts $\Rightarrow$ Learning Issues $=>$ Action Plan

Various problems structure PBL programs loosely according to this structure. For example, the Maastricht University program consists of a process which manifests Barrows' (1994) sequence in seven steps. At University College Cork, where the current author is situated, PBL sessions are structured as follows:

1. Assignment of roles, in which a chairperson and secretary are elected by learners;

2. Analyzing the problem by defining its content;

3. Remembering and discussing what is already known, either formally, informally or both;

4. Making hypotheses and imagining implications of hypotheses;

5. Structuring question as learning issues and ranking their relative importance;

6. Distributing academic work in which learners decide on who will research what;

7. Doing the work of resolving learning issues by accessing literature;

8. Reconvening, sharing and synthesizing knowledge in note form;

9. Clarifying knowledge by constructing concept maps or devising products related to the problem;

10. Re-reading the problem in the light of new found knowledge and relating these to the curriculum matrix;

11. Reflecting, giving feedback and making suggestions for the future.

Products and Concept Maps

At stage nine of the eleven point process, learners can clarify their knowledge by constructing visual summaries of their new-found understanding and knowledge in the form of concept maps. These concept maps, invented by Novak (1990) are a tool for organising and representing knowledge and are ideal for summarising a process of learning. The example below in Fig.1, is a concept map devised by first year learners pertaining to voice and laryngeal cancer, and is borrowed with permission from O'Toole (2006). Constructing concept maps allows learners to develop a taxonomy of knowledge and allows them to understand how differing sets of information relate to each other. Mok, Whitehill, and Dodd (2008, in press) discuss how concept maps relate to critical thinking in PBL.

Similarly, the learner could be asked to construct a product in relation to the problem. For example, in the sample problem provided above, learners were asked to role play a conversation together; or learners could be asked to write a short letter to a medical professional detailing issues in relation to a client. Similarly, learners can construct as a product, an information leaflet relating to the problem trigger. Learners can either construct products as a group, or produce these in preparation for tutorials, individually. Learners can be evaluated on the effort and meaningfulness of their products and concept maps.

\section{Reading Forms and Academic Journaling}

In addition to concept maps and products, learner's knowledge and synthesis of knowledge can be evaluated by setting them the task of writing short essays at the end of each problem, in which they apply their knowledge to the problem at hand. This involves either summarizing information if they are first year learners, or demonstrating their ability to apply relevant knowledge by applying academic content in relation to characters in a problem, if they are in second or third year. This permits the PBL facilitator, who marks these, to evaluate how deeply the learner was able to make sense and meaning of the literature; and provides the learner with an opportunity to formally demonstrate their relationship to knowledge. In addition, it provides the learner with opportunities to develop written skills. It is particularly valuable to learners when PBL facilitators provide feedback pertaining to the content and style of these reading forms. The writing of such applied summaries form one of the bases of continual assessment for the PBL curriculum.

In addition to reading forms, learners can submit an academic journal once a semester. This journal provides the PBL facilitator with a personal account of the learners' experiences of learning and their individual processes of academic development. Alternatively, such journals can be incorporated in the structure of the reading form.

\section{The Role of the PBL Facilitator}

Faculty lecturers, post-qualification $\mathrm{PhD}$ students, clinical tutors and other contracted speech and language therapists in the community can serve as PBL facilitators. Year co-ordinators divide up a year cohort into groups of 7 to 9 learners, who are allocated to a PBL facilitator for a semester at a time. Each group meets with their PBL facilitator for two to three-hour sessions in lieu of lectures; or with a few focused lectures pertinent to the problem under study.

According to Caplow and colleagues (1997), the effectiveness of the PBL facilitator's role can have a major 


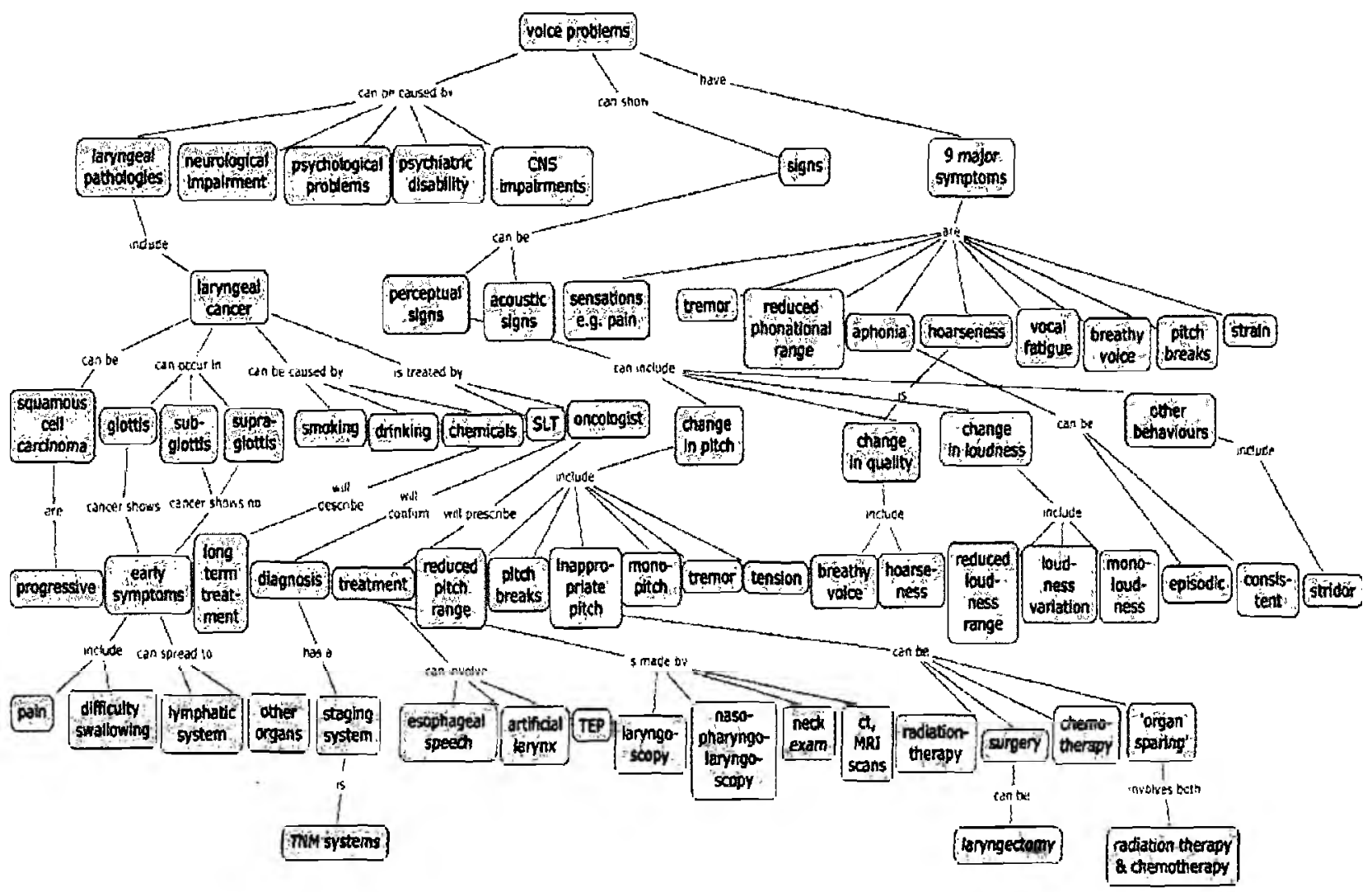

Fig 1. Example of Concept Map, used with permission from O'Toole (2006).

impact on the success of PBL outcomes in learners (Caplow, Donaldson, Kardash, \& Hosokawa, 1997). The skills employed in PBL are counter-intuitive and not often used in traditional pedagogies. Therefore, it is important that each PBL facilitator undergo some form of formal training in the facilitation of PBL tutorials.

Frost (1996) believes that the role of the PBL facilitator is to foster learners' exploration and reflection and thus enable them to achieve learning objectives. While some authors such as Wilkerson and Maxwell (1988) advocate that PBL facilitators remain silent for long periods, some PBL programs encourage facilitators to take an active role in guiding learners to explore learning areas. At University College Cork, PBL' facilitators use non-directive methods in facilitating learners by providing stimulating questions (Katz, 1995); providing alternate views and presenting learners with the consequences of their ideas (Schmidt, 1990). In addition, PBL facilitators can ask learners to justify their ideas, imagine the implications of their ideas and hypotheses, develop metacognitive skills (thinking about the learning process), apply concepts to learning issues and ensure that all learning issues are covered in sufficient depth. Also, the PBL facilitators concentrate on understanding the dynamics of the group (Hughes \& Lucas, 1997) and intervene when conflict hinders the process of learning (Wilkerson, Hafler, Liu, Schmidt, Van Der Arend, Moust, Koyx, \& Boon, 1992). 'Therefore PBL facilitators need to be trained to facilitate such groups; but the skill is easily learned and readily transmissible to others in the current author's experience.

PBL facilitators also evaluate individual students' engagement with the learning process from tutorial to tutorial, such as contribution to discussion and enquiry, and the demonstration of having read relevant texts, from tutorial to tutorial. This then represents another component of continual assessment in a PBL course.

Iterative evaluation of Problems

During the course of tutorials, PBL facilitators should keep notes on among other things, how the learners responded to the problem. This includes whether they identified all the learning issues as identified by the case manager; how they responded to the recommended literature; their affective response to the problem; and their overall interest in the problem. Learners often will provide criticisms of the problem; particularly if it is not ecologically valid; or if the recommended readings are above their developmental level. Learners can also be a source of ideas for changing the problem in terms of suggestions for learning areas and may sometimes identify sources of information, more relevant readings or websites that were useful to them. These can be fed back to case managers for future iterations of the problem. Case managers, PBL facilitators and year cocoordinators can then review facilitators' notes at an annual curriculum committee meeting; and use such feedback to modify, extend or change problems to better reflect clinical practice and reasoning, available literature, learners' actual elicited learning issues, as well as new developments in the literature. Following this meeting, case managers make their modifications and submit their re-written problems to the year co-ordinators who then compile the revised problems into a book of problems which is published in anticipation of the next year of upcoming learners. Listening to learners' ideas is an extremely valuable way of improving the quality and educational value of the problems. Problems themselves 


\section{ROBERT FOURIE}

are therefore dynamic and ever-changing; reflecting the changing nature of the field of communication disorders, the changes in available information, the changing needs of clients and the changing needs of SLP learners.

Situating problems in semester times

A set of problems needs to be divided into the semester structure of an SLP course. How much time is spent on each problem, depends on its complexity, the amount of recommended reading and how many learning areas are covered in the problem. Some SLP curricula cover one problem per week or week and a half, while other curricula cover two very detailed problems over a whole semester. It is up to the curriculum committee to determine how much of the course will be covered in PBL tutorials.

Table 1. below is a visual representation of PBL tutorials structured over four times based on a curriculum framework in which the majority of the curriculum is delivered by PBL tutorials. In this curriculum, there are between ten and fifteen problems per year. If in the first year, fourteen problems are covered over two twelve-week semesters the problems can be structured as in Table 1, below. Typically, learners meet four times per problem in this time structure. However, time 1 and time 4 involve the end of one problem and the beginning of another. Thus problems are staggered over periods that last approximately a week and a half.

Table 1. A visual representation of tutorials structured over four times

The relationship of the PBL curriculum to the rest of the

coincide with and elucidate the topics covered in PBL; and can therefore present learners with an opportunity to apply theoretical knowledge in practice.

\section{Evaluation and Examination of PBL Learners}

Various PBL programs assess students in different ways. At the SLP programme at UCC, assessment is ongoing, and learners are evaluated on the basis of:

(i) Contributions to PBL tutorials;

(ii) Evidence of having engaged in reading for the problem;

(iii) Reading forms and academic journals;

(iv) Formal examinations.

As (i) to (iii) above have already been discussed in this paper, a process of PBL examination is outlined below.

A week prior to the examination date, learners are individually provided with an examination problem. This problem is a new learning opportunity that provides content not necessarily, or partly covered in previous PBL problems. In addition, learners are provided with appropriate references or readings pertaining to the problem. Learners are expected to read all references in addition to their own further reading. During the examination, which is typically three hours in duration, learners may make reference to all unmarked readings, which they are permitted to bring to the examination. They may not bring in additional texts or any notes pertaining to the problem. The examination questions are devised from a Constructivist perspective, i.e., they are written in such a way as to provide learners with an opportunity to demonstrate their ability to apply information and clinical reasoning appropriately to

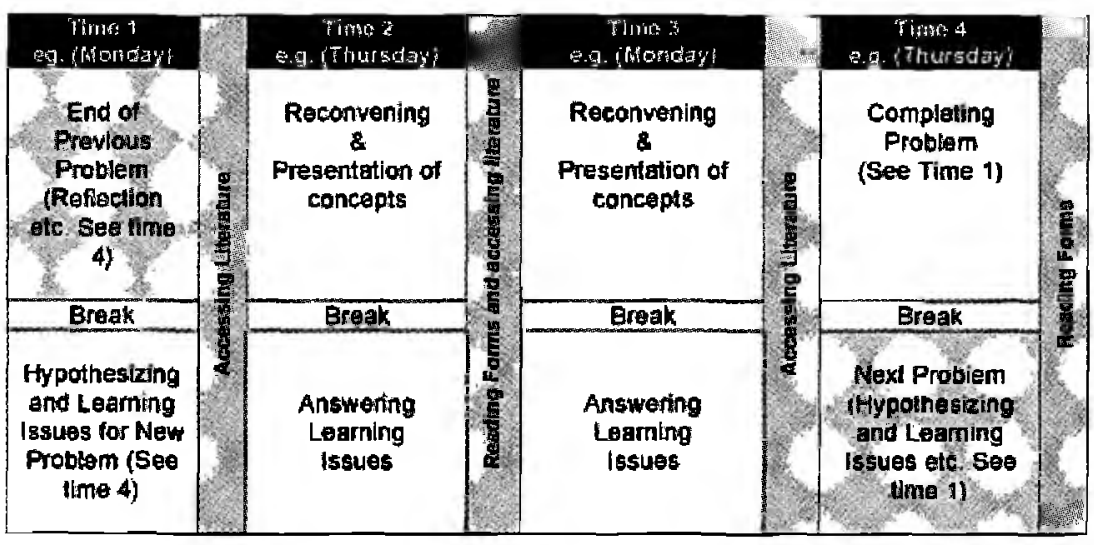

the examination problem statement. Therefore, factual information is elicited; but the focus in examinations is on how students can use various sources of information to construct coherent and meaningful applications to a clinical problem; thus demonstrating their knowledge in relation to information. Consequently, memorisation of factual information is less important than reasoning, application and a coherent discussion of the learner's learning issues: An example of an examination question relevant to the problem, "Voice Spasm", cited above may be:

\section{curriculum}

It is probably unrealistic to expect that the entire academic content of any program could be delivered by PBL alone. In addition to conceptual and affective learning, learners need to be able to do things relating to a profession. These activities are referred to as psychomotor skills. In SLP curricula, this could refer to learning how to use instrumentation to analyze voice; or it may involve being shown how to administer a psycholinguistic assessment; or it may involve being shown how to work with a client in therapy. All of these skills require procedural knowledge that are not necessarily accessibly from a PBL curriculum or a traditional curriculum. Therefore, in addition to a PBL curriculum, the faculty needs to consider that learners may need supporting workshops and lectures which generally
(1) Explain why differential diagnosis of spasmodic dysphonia was so difficult for the professionals involved in Thandi's case. In addition, provide a reasoned discussion of how Dr N thebe's evaluation of Thandi's lack of improvement led to a more accurate diagnosis; and what implications this might have for the general practice of SLP.

Such an examination question requires learners to think, reason and apply information to an iconic clinical situation and reflects the ethos of the PBL format of teaching and learning. Of course, faculty members can devise their own methods of assessment that honour the PBL format, but these should consider the learners' developmental level and the time implications of such assessments; and should not focus on the learners' abilities to memorize facts. In the current author's experience, many existing SLP programmes 
already structure examination questions in such a format.

\section{Conclusion}

The current paper provides only a brief introduction to $\mathrm{PBL}$; and the interested reader is referred to a plethora of available literature on the implementation of a PBL curriculum. Constructing a PBL curriculum involves a good deal of planning and curricular consideration on the part of academic staff. However, there are a number of benefits to this, not least the promotion of life-long, active learning in both learners and in faculty staff. Academic staff tend to be more aware of the overall curriculum and how lecturing serves the purpose of elucidating on problems and learning issues formulated by learners themselves, in response to problem triggers. Moreover, learners are keen to learn because they are invested and involved in the curriculum - and this in itself is highly psychologically motivating and satisfying for curriculum designers and faculty staff. Accordingly, it motivates faculty staff to update their curriculum, provide better exemplars of learning and to keep abreast with current developments in a particular learning area or topic. By working together in small groups, academic staff and learners get to know each other, thus facilitating professional socialization. Moreover, the work environment becomes rich in feedback loops - thus improving communication as a whole within an SLP programme. In conclusion, the following quote from W.B. Yeats summarizes the current author's thoughts about the use of PBL:

\section{"Education is not the filling of a bucket, but the lighting of a fire." \\ - WB Yeats}

\section{References}

Anspach, R. R. (1988). Notes on the sociology of medical discourse, Journal of Health and Social Behavior, 28, 357-375.

Barrows, H. (1994). The tutorial process. Springfield: Southern Illinois University School of Medicine.

Barrows, H. S. (1996). Problem-Based Learning in Medicine \& Beyond: A Brief Overview, New Directions for Teaching \& Learning, 68, 3-12!

Barrows, H. S. (1998). The essentials of problem-based learning. Journal of Dental Education, 62(9), 630-633.

Barrows, H. S. (2000). Problem-based learning applied to medical education. Springfield: Southern Illinois University School of Medicine.

Barrows, H., \& Kelson, A. C. (1995).Problem-Based Learning in Secondary Education and the Problem-Based Learning Institute (Monograph 1), Springfield: Problem-Based Learning Institute.

Bereiter, C., \& Scardamalia, M. (1989). Intentional learning as a goal of instruction. In L. B. Resnick (Ed.), Knowing, learning, and instruction: Essays in bonor of Robert Glaser (pp. 361-392). Hillsdale, NJ: Lawrence Erlbaum Associates.

Biggs, J. (2003). Teaching for Quality Learning at University, $2^{\text {nd }}$ ed, Buckingham: The Society for Research into Higher Education \& Open University Press.

Blumer, H. (1969). Symbolic Interactionism: Perspective and Metbod. New Jersey: Prentice Hall, Inc.

Bloom B. S. (1956). Taxonomy of Educational Objectives, Handbook
I: The Cognitive Domain. New York: David McKay Co Inc.

Bonk, C. J., \& Cunningham, D. J. (1998). Searching for learner-centered, constructivist, and sociocultural components of collaborative educational learning tools. In C. J. Bonk, \& K. S. King (Eds.), Electronic collaborators: Learner-centered technologies for literacy, apprenticeship, and discourse (pp. 25-50). Mahwah, NJ: Erlbaum.

Carder, L., Willingham, P., \& Bibb, D. (2001). Case-based, problem-based learning: Information literacy for the real world, Research Strategies, 18(3), 181-190.

Caplow, J. H., Donaldson, J. F., Kardash, C. A., \& Hosokawa, M. (1997). Learning in a Problem-Based Medical Curriculum: Students' Conceptions, Medical Education, 31, 1-8.

Carroll, D. W. (1994) Psychology of language. $2^{\text {nd }}$ edition. California: Brooks/Cole Publishing Company.

Cacioppo, J. T., \& Petty, R. E. (1982). The need for cognition. Journal of Personality and Social Psychology, 42(2), 116-131.

Chambliss, M. J. (1995). Text cues and strategies successful readers use to construct the gist of lengthy written arguments. Reading Research Quarterly, 30, 778-807.

Collins, A., Brown, J. S., \& Newman, S. E. (1989). Cognitive apprenticeship: Teaching the crafts of reading, writing, and mathematics. In L. B. Resnick (Ed.), Knowing, learning, and instruction:Essays in honor of Robert Glaser (pp. 453-494). Hillsdale NJ: Erlbaum.

Colliver, J. A. (2002). Educational theory and medical education practice: a cautionary note for medical school faculty, Academic Medicine, 77, 1217-1220.

Cummins, J. (1984). Bilingualism and special education. San Diego, CA: College Hill Press.

Cummins, J. (1986). Empowering minority students: A framework for intervention. Harvard Educational Review, 56, 18-36.

Dewey, J. (1929). The sources for a science of education. New York: Horace Liveright.

Dole, J. A., \& Sinatra, G. M. (1998). Reconceptualizing change in the cognitive construction of knowledge. Education Psycholo$g^{i s t,}$ 22, 109-128.

Dolmans, D. H. J. M. (1997). Seven principles of effective case design for a problem-based curriculum, Medical Teacher, 19(3), 185-189.

Festinger, L. (1957). A Theory of Cognitive Dissonance. Evanston, IL: Row, Perterson \& Company.

Frost, M., (1996). An analysis of the scope and value of problem based learning in the education of health care professionals. Journal of Advanced Nursing, 24 (5), 1047-1053.

Fourie, R. J. \& Fletcher, P. J. (2006). Attitudes of 1st year SLT Students in Ireland to PBL, Paper presented at the First Conference on PBL in Speech Language Pathology Programmes, Linköping, Sweden, May 2006.

Garner, R., Alexander, P. A., Gillingham, M. G., Kulikowich, J. M. \& Brown, R. (1991). Interest and learning from text, American Education Research Journal, 28(3), 643-659.

Gonzalez, M. L., \& Salmoni, A. J.(2008). Online problem-based learning in postgraduate medical education - content analysis of reflection comments, Teaching in Higher Education,13(2),183192.

Haith-Cooper, M. (2000). Problem-based learning within health professional education. What is the role of the lecturer? A review of the literature. Nurse Education Today, 20(4): 267-272.

Hidi, S. (1990). Interest and its contribution as a mental resource 


\section{ROBERT FOURIE}

for learning. Review of Educational Research, 60(4), 549-571.

Hidi, S., \& Baird, W. (1988). Strategies for increasing text-based interest and students' recall of expository texts. Reading Research Quarterly, 23, 465-483.

Hmelo-Silver, C. E. (2004). Problem-based learning: What and how do students learn? Educational Psychology Review, 16(3), 235-266.

Hmelo-Silver, C. E., \& Barrows, H. (2006). Goals and strategies of a Problem-based learning facilitator, The Interdisciplinary Journal of Problem-based Learning, 1, 21-39.

Hughes, L., \& Lucas, J. (1997). An evaluation of problem based learning in the multiprofessional education curriculum for the health professions, Journal of Interprofessional Care, 11, 77-88.

Katz, G. (1995). Facilitation. In C. Alavi (Ed.), Problem-based Learning in a Healtb Sciences Curriculum (pp. 52-71). London: Routledge.

Koh, G. C., Khoo, H., Wong, M. L., \& Koh, D. (2008). The effects of problem based learning during medical school on physician competency: A systematic review, Canadian Medical Association Journal, 178, 34-41.

Leahy, M. M., Dodd, B. J., Walsh, K., \& Murphy, K. (2006). Education for practice in the UK and Ireland: Implementing problem-based learning, Folia Phoniatrica et Logopaedica, 58(1), 48-54.

Miller, A. (2000). "Realism", The Stanford Encyclopedia of Philosophy, In E. N. Zalta (Ed.), Downloaded from <http://plato. stanford.edu/archives/fall2005/entries/realism/> 13/02/2008.

Mok, C., Whitehill, T. L., \& Dodd, B. (2008, in press). The interrelationship between problem-based learning, critical thinking and concept mapping in speech-language pathology education: A review. International Journal of Speech-Language Pathology, 10(6), 1-11.

Murphy, K. (2004). Student perceptions of the advantages and disadvantages of problem based learning, Journal of Clinical Speech \& Language Studies, 14, 64-76.

Neighbour, R. (1992). The inner apprentice. Plymouth: Petroc Press.

Norman, G. R. \& Schmidt, H.G. (1992). The psychological basis of problem-based learning: A review of the evidence. Academic Medicine, 67, 557-565.

Novak, J. D. (1990). Concept maps and Vee diagrams: Two metacognitive tools for science and mathematics education. Instructional Science, 19, 29-52.

Osler, W. (1913). Examinations, examiners and examinees. Lancet, 185, 1047-1050.

O'Toole, C. (2006). Using concept maps and products in Problem
Based Learning. Poster presented at the First Conference on PBL in Speech Language Pathology Programmes, Linköping, Sweden, May 2006.

Palincsar, A. S. (1998). Social constructivist perspectives on teaching and learning, Annual Review of Psychology, 49, 345-375.

Renninger, K. A. (2000). Individual interest and its implications for understanding intrinsic motivation. In C. Sansone \& J. M. Harackiewicz (Eds.), Intrinsic motivation: Controversies and new directions (pp. 373-404). New York: Academic Press.

Rogers, C. R. (1961) On Becoming a Person. A therapist's view of psycbotherapy, Boston: Houghton Mifflin.

Saettler, P. (1990). The Evolution of American educational Technology. Libraries Unlimited Inc, Englewood.

Savery, J. R. \& Duffy, T.M. (2001). Problem based learning: An instructional model and its constructivist framework (Tech. Rep. No. 16-01). Indiana University, Centre for Research on Learning and Technology.

Schank, R. C. (1979). Interestingness: Controlling inferences. $A r-$ tificial Intelligence, 12, 273-297.

Schmidt, H. (1990). Educational aspects of problem-based learning. In: W. Jochems (Ed). Aktiverend Onderwijs, Delft University Press.

Shirey, L. L., \& Reynolds, R. E. (1988). Effect of interest on attention and learning. Journal of Education Psychology, 80, 159166.

Stein, N., \& Glenn, C. (1979). An analysis of story comprehension in elementary school children. In R. Freedle (Ed.), New Directions in Discourse Processing, 2, 53-120.

Thorndike, E. L. (1906). The Principles of Teaching, Based on Psychology. New York: Seiler.

Thorndyke, P. W. (1977). Cognitive Psychology. New York: Academic Press.

Vygotsky, L. S. (1981). The instrumental method in psychology. In J. V. Wertsch (Ed.), The concept of activity in Soviet psycbology (pp. 134-143). New York: Sharpe.

Wilkerson, L., Hafler, J., Liu, P., Schmidt, H., Van Der Arend, A., Moust, J., Koyx, I., \& Boon, L. (1992). Influence of tutors' subject matter expertise on students' effort and achievement in problem-based learning. Academic Medicine, 68, 784- 791.

Wilkerson, L., \& Maxwell, J. (1988). A qualitative study of initial! faculty tutors in a problem-based curriculum. Journal of Medical Education, 63, 892-899.

Wood, E. J. (2004). Problem Based Learning, Acta Biochimica Polonica, 51(2), 21-26. 